\title{
Assessing the impacts of climate variability and climate change on biodiversity in Lake Nakuru, Kenya
}

\author{
MBOTE BETH WAMBUI ${ }^{1}$, ALFRED OPERE ${ }^{1, \vartheta}$, JOHN M. GITHAIGA ${ }^{2}$, FREDRICK K. KARANJA ${ }^{3}$ \\ ${ }^{1}$ Department of Meteorology, School of Physical Sciences, University of Nairobi. P.O. Box 30197-00100, Nairobi, Kenya. \\ vemail: bethmbote@gmail.com, aopere@uonbi.ac.ke \\ ${ }^{2}$ School of Biological Sciences, University of Nairobi. Nairobi, Kenya \\ ${ }^{3}$ Department of Meteorology, University of Nairobi. Nairobi, Kenya
}

Manuscript received: 7 December 2017. Revision accepted: 15 May 2018

\begin{abstract}
Wambui MB, Opere A, Githaiga MJ, Karanja FK. 2018. Assessing the impacts of climate variability and climate change on biodiversity in Lake Nakuru, Kenya. Bonorowo Wetlands 8: 13-24. This study evaluates the effects of the raised water levels and the flooding of Lake Nakuru and its surrounding areas on biodiversity, specifically, the phytoplankton and lesser flamingo communities, due to climate change and climate variability. The study reviewed and analyzed noticed climatic records from 2000 to 2014 . Several methods were used to ascertain the past and current climatic parameters (temperature, rainfall, and evaporation) and the physicochemical characteristics of Lake Nakuru (conductivity, phytoplankton, lesser flamingos, and the lake depth). These included time series analysis and trend analysis, so Pearson's correlation analysis was used to show a relationship between the alterations in lake conductivity to alterations in population estimates of the lesser flamingos and the phytoplankton. Data set extracted from the Coupled Model Inter-comparison Project Phase 5 (CMIP5) (IPCC Fifth Assessment Report (AR5) Atlas subset) models were subjected to time series analysis method where the future climate scenarios of near-surface temperature, rainfall, and evaporation were plotted for the period 2017 to 2100 (projection) for RCP2.6 and RCP8.5 relative to the baseline period 1971 to 2000 in Lake Nakuru were analyzed. The results were used to evaluate the impact of climate change on the lesser flamingos and phytoplankton abundance. It was noticed that there was a raise in the mean annual rainfall during the study period (2009 to 2014), which brought the increment in the lake's surface area from a low area of $31.8 \mathrm{~km}^{2}$ in January 2010 to a high of $54.7 \mathrm{~km}^{2}$ in Sept 2013, indicating an increment of $22.9 \mathrm{~km}^{2}(71.92 \%$ surface area increment). The mean conductivity of the lake also lessened, leading to the loss of phytoplankton on which flamingos feed, making them migrate. A strong positive correlation between conductivity and the lesser flamingo population was noticed, signifying that low conductivity affects the growth of phytoplankton. Since the lesser flamingos depend on the phytoplankton for their feed, this subsequently revealed that the phytoplankton density could be a notable predictor of the lesser flamingo occurrence in Lake Nakuru. A strong positive correlation was noticed between phytoplankton and the lesser flamingo population confirming that feed availability is a key determining factor of the lesser flamingo distribution in the lake. It is projected that there would be an increment in temperatures, rainfall, and evaporation for 2017 to 2100 under RCP2.6 and RCP8.5 relative to the baseline period 1971 to 2000 obtained from the Coupled Model Inter-comparison Project phase 5 (CMIP5) multi-model ensemble. As a result, it is expected that the lake will further increment in surface area and depth by the year 2100 due to increased rainfall, thereby affecting the populations of the lesser flamingos and phytoplankton, as the physicochemical factors of the lake will alter as well during the projected period.
\end{abstract}

Keywords: Biodiversity, climate change, Lake Nakuru, Kenya

\section{INTRODUCTION}

Africa has been known as one of the most easily damaged regions in the world regarding climate change, according to the Fourth Assessment Report from the Intergovernmental Panel on Climate Change (IPCC 2007). A report stated that some areas in Africa evidently are highly vulnerable to climate variability and change. Kenya's current climate predictions have forecasted increased changes and variability of different climatic factors. Severe challenges to sustainable development are being propounded by climate change in Kenya, as it's possibly a significant environmental challenge of our time (Mutai et al., 2010). Focusing on the effects of climate change on water resources, coastal zones, ecosystems, health, industrial activity, food, and human settlements propounds chances for improved livelihoods, business, and innovation.
Various patterns of rainfall and rising temperatures have also worsened the problem of wetlands drying out, thereby threatening water availability leading to lessened agricultural production and thus accruing food insecurity due to lessening yields in crops. Various rainfall patterns have posed threats to the renowned wildlife safaris in Kenya, especially to one of the Seven Wonders of the World: The Mara River migration of wildebeests, which is familiar to tourists around the world (Climate Action Network 2009). Irregular rain patterns affect the wildebeests as the smell of rain influences their migration. The migration pattern is usually timed to show a relationship between the growth of grass and annual rainfall patterns in the North. Drawing closer to March, characterized by a season of temporary dryness, the wildebeests begin migrating from Serengeti as the grass starts drying out towards the western Serengeti woodlands. By the end of June, when the long rains commence 
declining in Kenya, the arrival of wildebeest from the Western Serengeti is noticed in the Maasai Mara Game Reserve. Due to unpredictable climate, scarce feeding vegetation, and the drying-up of rivers have caused considerable losses in wildlife numbers (Climate Action Network 2009).

There is a wide variety of wildlife and ecosystems in Kenya, populating in air, water, and land. Biodiversity assets known in Kenya include 7,000 plant species, 315 mammals, 1,133 birds, 25,000 invertebrates (21,575 of which are insects), 191 reptiles, 692 marine and brackish fish, 180 freshwater fish, 88 amphibians, and about 2,000 species of fungi and bacteria (NEMA 2009a). Kenya boasts a large population of mammalian species' ranking it third in Africa, with fourteen of these species being endemic (IGAD 2007). Large mammals such as the African elephant (Loxodonta africana), leopard (Panthera pardus), black rhino (Diceros bicornis), African lion (Panthera leo), and buffalo (Syncerus cafer) have made the country popular due to their diverse nature (NEMA 2009a). According to the IUCN Threat Criteria (2008), 146 plant species of the 7000 found in Kenya have been assessed, with 103 being classified as threatened (vulnerable, endangered, or seriously endangered) (NEMA 2011).

In Kenya, threats to biodiversity have been on the increment over the past decades due to human-wildlife conflicts, habitat loss, population increment, and infrastructure development, global climate change, pollution, biopiracy, poaching and overexploitation, invasive alien species, and biosafety concerns (Government of Kenya (GoK), National Environment Management Agency (NEMA 2011). In this regard, safeguarding this biodiversity will be critical to securing livelihoods resulting in reduced poverty levels - reflecting a population of 46.6 percent - suggesting a nine percent alteration if the social equity scales are to be attained as projected by Vision 2030's social pillar (NEMA 2011).

Provided crucial coping, mitigation, and adaptation approaches are realized, future climate variability and climate change impacts can be avoided, delayed, or reduced. About US \$500 million per year was needed in Kenya to address the climate change effects by 2012 (Stockholm Environment Institute 2009). The US \$1-2 billion per year was the amount this figure was forecasted to raise by 2030 (Stockholm Environment Institute 2009). The collective effect of impacts of climate change will limit the realization of Vision 2030 targets unless there is an urgent institutionalization of effective adaptation and mitigation mechanisms. A range of policy instruments needs to be formulated to tackle climate change. A national policy on climate change needs to be formulated and a climate change law further enacted, recognizing that the National Climate Change Response Strategy (NCCRS) was finalized in 2010. The country will be economically affected by the impacts of climate change and its biodiversity heritage.

The main objective of the research was to evaluate the impacts of climate variability and climate change on Lake Nakuru's biodiversity, Kenya, i.e., (i) to estimate the trends of past and present climatic records, and especially the temperature, rainfall, and evaporation, of Lake Nakuru basin to understand the causes of increased lake levels. (ii) to show a relationship between lake conductivity alterations to alterations in aquatic species' population estimates, especially the phytoplankton and the lesser flamingos of Lake Nakuru basin. (iii) Evaluate in light of future climate projections, especially temperature, rainfall, and evaporation, the likely impacts of climate change on Kenya's biodiversity, especially the lesser flamingos and phytoplankton in the Lake Nakuru basin.

\section{MATERIALS AND METHODS}

\section{Area of study}

The study site was Lake Nakuru; it was chosen because it is one of the most important habitats for the flamingo species and one of Kenya's important tourist destinations. Lake Nakuru National Park, Kenya is located between $0^{\circ} 19^{\prime}-0^{\circ} 24^{\prime} \mathrm{S}$ and $36^{\circ} 04^{\prime}-36^{\circ} 07 \mathrm{E}$, approximately $3 \mathrm{~km}$ south of Nakuru town, Kenya. It lies in a graben between Lion Hill fracture zone in the east and a series of east downthrown step-fault scarps leading to the Mau Escarpment to the west.

Lake Nakuru extends in the N-S direction in the trend of the axial rift faults, as shown by Figure 1. It includes other chains of alkaline-saline lakes in the eastern arm of the Rift Valley, Kenya. Existing more than twelve million years, one of the earth's spectacular geological formations was formed by the catchment and its landforms, including rifts, cliffs, mountains, volcanoes, and lakes (Odada et al. 2006). Progressions of characteristics and features that describe Lake Nakuru have been influenced by climate, evolutionary history, and Geography. Levels of productivity and successful establishment of species have been ascertained by these features, which set the chemistry of the lakes' water. The lake's ecosystem is made unique by the chemistry of the alkaline water, which depends on the larger catchment for sustenance and is independent of its immediate environment for its functions. White salt filets swirling with dust devils are sometimes created when enormous water body reductions result from the lake's surface area alterations.

\section{Data type}

Data used in this study included climatic data comprising of mean annual temperature, mean annual rainfall mean annual evaporation, and the Coupled Model Inter-comparison Project Phase 5 (CMIP5) Representative Concentration Pathways (RCP2.6 and RCP8.5) nearsurface temperature, rainfall, and evaporation data. Lake data comprised conductivity, lake levels, surface area, and depth. Flamingo data consists of the lesser flamingo population. Below is a detailed description of the data types and their sources.

\section{Procedures}

In this section, the methods used in the study for data collection, organization, and analysis based on the study's specific objectives are propounded. 


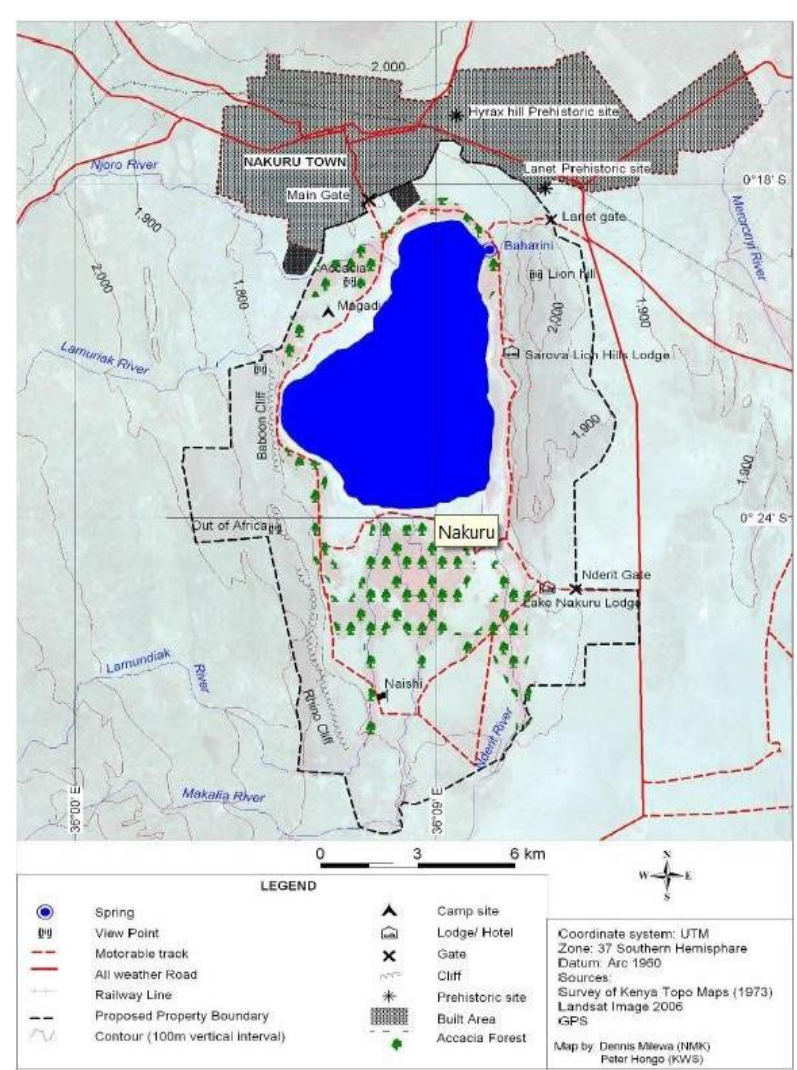

A

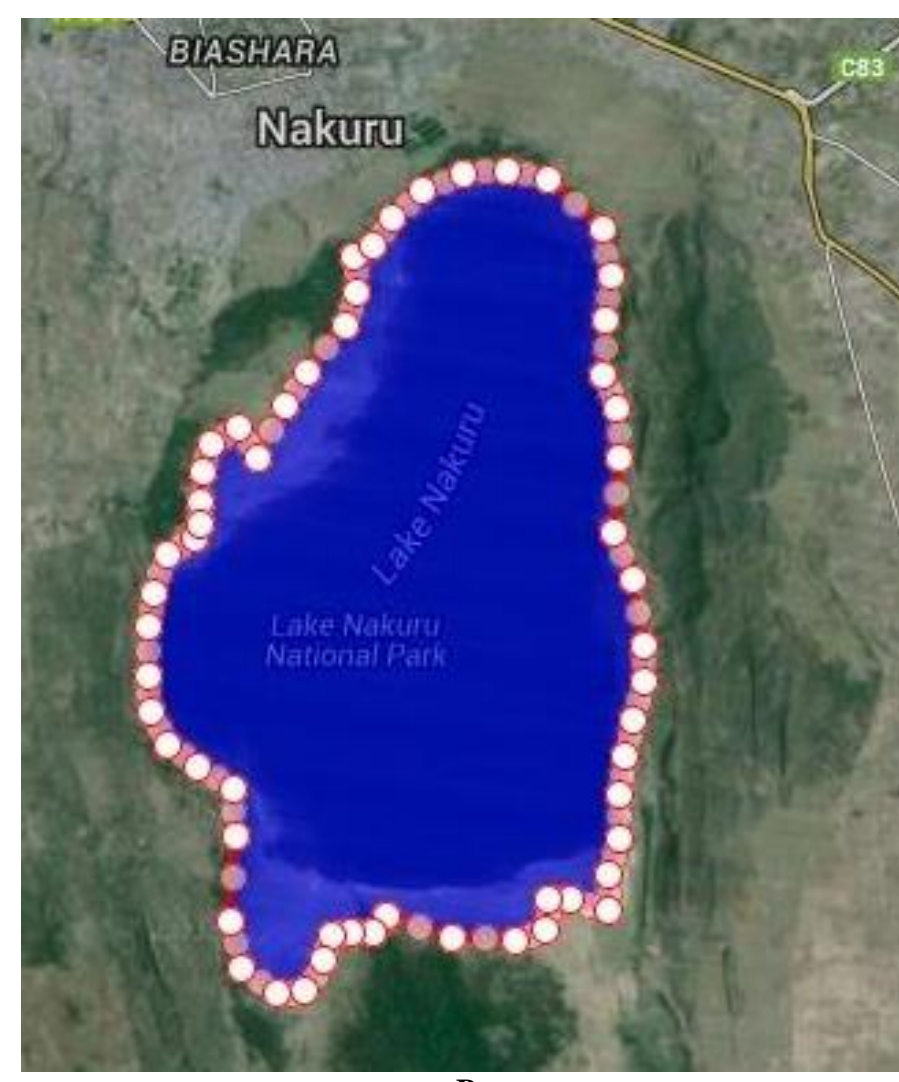

B

Figure 1. A. Map of Lake Nakuru, Kenya, showing detailed geographic features. B. Current surface area (April 2016) of Lake Nakuru $(54.8 \mathrm{~km} 2)$ as noticed from Google maps area calculator tool from the internet (Source: Adapted from Google maps, April 2016)

\section{Study design and sample size determination}

Sample and sample size identification was purposive and quantitative. Four sites, Nderit, Makalia, Baboon Cliff, and Lion Hill, were selected as sampling sites/stations for collecting water samples used to ascertain the levels of phytoplankton population densities, species composition, and conductivity measurements in the lake in 2014. The sampling sites were broadly ascertained by their accessibility as the lake was entirely flooded, leading to the loss/damage of the road infrastructure, which limited access to other sites. Water samples from the lake were collected in four replicates, fortnightly, in August 2014 and the first half of September 2014. The study sought to investigate the impact of climate variability and climate change on Lake Nakuru's biodiversity on the following indicators: (i) Lake levels (surface area and depth), (ii) Conductivity levels, (iii) Alteration in species populations of the phytoplankton and the lesser flamingos.

\section{Data sources}

Field visits and preliminary assessments. The water samples collected were used to ascertain the levels of phytoplankton population densities, species composition, and conductivity measurements in the lake in 2014. These measurements were compared with data acquired from the Kenya Wildlife Service database from 2009 to 2014. Samples were collected in sterile bottles and transported in a cool box to the School of Biological Sciences laboratory,
Chiromo Campus, the University of Nairobi, where ex-situ measurements of conductivity and phytoplankton concentration were conducted. Before analysis, the samples were stored in a fridge in the laboratory.

A Hanna Multi-parameter Water Analyzer Model HI 9828 was used to measure the conductivity of the water samples collected. The mean value of the four replicates was ascertained for each sampling site which was used to compute the mean conductivity of the lake. One replicate from each site was randomly selected to determine the phytoplankton cells concentration and species identification. $1 \mu \mathrm{L}$ was taken from the bottle, suspended, and centrifuged in $100 \mu \mathrm{L}$ sterilized water. $1 \mu \mathrm{L}$ of this suspension was placed on a glass slide and noticed under a LEICA DM500 microscope where the number of individuals in the field of view (quadrant) were counted and identified. This process was replicated for the other samples.

Populations of lesser flamingos. Data on population estimates of the lesser flamingos in the lake from 2009 to 2014 was collected from the KWS Bi-annual Waterfowl Count Report- Kenya Rift Valley Lakes ascertained using a modification of a method as described by (Pomeroy \& Dranzoa, 1997). The information was used to ascertain the recent population trends and movement patterns of lesser flamingo in the context of flooding and the extensive dilution of the lake and show a relationship between the alterations in lake conductivity to alterations in the 
population estimates of the phytoplankton and lesser flamingo for the period 2009 to 2014 . The data was based on the January waterbird counts conducted jointly by the National Museums of Kenya and Kenya Wildlife Service.

Alterations in the lake levels. Data to ascertain the lake surface area and depth alterations were obtained from (Onywere et al. 2013) and the Kenya Wildlife Service records, respectively. Documentation of the lake surface area alterations was made using Geographic Information System (GIS) digital techniques and information extraction and representation from Landsat satellite image data for January 2010, May 2013 and September 2013, and October 2013 (Onywere et al. 2013). In contrast, monthly measurements of the lake's depth were collected from KWS. This had been ascertained from the readings of a staff gauge located at the lake center.

Physicochemical characteristics of water (phytoplankton concentration and conductivity). The physicochemical qualities of water (phytoplankton concentration and conductivity) for 2009-2013 were obtained from the Kenya Wildlife Service (KWS) database. Monthly measurements of conductivity and concentration of phytoplankton in lake water had been ascertained based on monthly analysis of water taken from the lake center. Conductivity had been ascertained using a $\mathrm{pH}$ meter. The concentration of phytoplankton had been ascertained using the Sedgewick-Rafter counting chamber as described by Kimberly (1999).

Noticed climate data. The climatic data (rainfall, temperature, evaporation) for 2009 to 2014 was collected from the Kenya Meteorological Department, based on monthly data from the Nakuru Meteorological Station $9036261\left(0.28^{\circ} \mathrm{S}, 36.1^{\circ} \mathrm{E}\right)$, located $3 \mathrm{~km}$ north of the lake at the Nakuru Agricultural show grounds.

Climate projection data sets. In this study, the projected alterations in near-surface temperature, rainfall, and evaporation for Lake Nakuru have been extracted from the Coupled Model Inter-comparison Project Phase 5 (CMIP5) multi-model ensemble (IPCC Fifth Assessment Report (AR5) Atlas subset) models. The output data were extracted as a relative alteration from 1971 to 2000 (baseline) to 2017 to 2100 (projection) under two scenarios, namely, the RCP2.6 and RCP8.5 scenarios (Taylor et al., 2012). The RCP2.6 and RCP8.5 represent 'low' (RCP2.6) and 'high' (RCP8.5) scenarios featured by the radiative forcing of 2.6 and $8.5 \mathrm{Wm}-2$ by 2100 , respectively. The $\mathrm{CO} 2$ equivalent concentrations in the year 2100 for RCP 2.6 and RCP 8.5 are 490 ppm and 1370 ppm, respectively (Moss et al. 2010). RCP2.6 and RCP8.5 were chosen for this study as RCP2.6 describes an all-out effort to limit global warming to below $2{ }^{\circ} \mathrm{C}$ with emissions lessening sharply after 2020 and zero from 2080 onward, whereas RCP8.5 describes a business-as-usual scenario with accruing greenhouse gas emissions over time, leading to high greenhouse gas concentration levels.

These Representative Concentration Pathways (RCPs) are among four new GHG concentration-developed scenarios set containing emission, concentration, and landuse trajectories, which have been adopted by the IPCC Fifth Assessment Report (AR5) (Moss et al. 2010; Van
Vuuren et al. 2011; IPCC 2014). They describe possible climate futures explaining the possible range of forcing values up to 2100, concerning the situation before industrialization. RCP2.6 and RCP8.5 were chosen for this study as they

\section{Data quality control}

Data quality control was conducted to ensure that the data sets were devoid of missing values, consistent, uniformly entered, and arranged to facilitate further processing. The data were then subjected to various statistical computations.

Homogeneity test. Most long-term climatological data records have been affected by several non-climatic factors that make these records unsuitable for comparison over long periods and between different stations. These relate to alterations affecting instruments, sites, procedures, observations, and data processing methods. These factors are caused by alterations in instrumentation, observation practices, location of the station, and formulae used for means calculation and changing the station's environment. While some alterations make critical discontinuities, others, particularly alterations around station environment, due, for example, urbanization, causes data biases which are gradually leading to time series biases and studied climate misinterpretations. In this study, the cumulative mass curve technique described in the subsection below was used to test for data homogeneity.

Mass curve. Mass curve analysis entails plotting cumulative climatological data records against time to depict the homogeneity. The patterns of these graphs can be used to test for the quality of the records. A single straight line indicates a homogeneous record, whereas heterogeneity tendency is indicated by the existence of more than one line fitted to the graphical plots of the cumulative data. For the heterogeneous records, correcting the heterogeneity would be the next step. Double mass curves are commonly used to adjust heterogeneous records whose principles are similar to those of mass curves. In this study, the single mass curve technique was used to test the data consistency where cumulative rainfall and temperature data were plotted against time to depict the homogeneity. A straight-line graph depicted homogeneous data.

\section{Time series analysis}

Time series is the organization of statistical data in chronological order and its time of occurrence. Using the graphical method, this study plotted the annual means of rainfall, temperature, and evaporation data for 2000 to 2014. In addition, annual data means for lake depth, lesser flamingo population, conductivity, and phytoplankton levels for 2009 to 2014 were also plotted.

To ascertain the projected alterations in near-surface temperature, rainfall, and evaporation for Lake Nakuru, data extracted from the Coupled Model Inter-comparison Project Phase 5 (CMIP5) multi-model ensemble (IPCC Fifth Assessment Report (AR5) Atlas subset) models were plotted using the KNMI (2015) to analyze the data for the period 2017 to 2100 for RCP2.6 and RCP8.5 relative to the baseline period 1971-2000. 
The trend is characterized by the long-term movement that is either represented by growth or decline in a time series through a lengthy period. The trend in time series in this study, the graphical method was used to ascertain the past and current trends of climatic parameters (temperature, rainfall, and evaporation) and the physicochemical characteristics of Lake Nakuru (conductivity, phytoplankton, lesser flamingos, and the lake depth).

Standard error of the mean was used to provide information about the distribution of the values within the trends, as shown by Equation (1).

$$
\sigma_{M}=\frac{\sigma}{\sqrt{N}}
$$

Where, $\sigma \mathrm{M}$ is the standard error of the mean, $\sigma$ is the standard deviation of the original distribution, and $\mathrm{N}$ is the sample size (the number of counts each mean is based upon). Specifically, in this study, the error bars were fitted graphically to evaluate whether there was a notable difference between the data sets. While a larger sample size suggests a smaller standard error of the mean, overlapping error bars imply that the difference is usually not notable. However, when the error bars do not overlap, it suggests that the difference is notable.

\section{Correlation analysis}

The Pearson Correlation coefficient (r), given in equation (2), was used to quantify the degree of relations between pairs of study variables. It is used extensively to measure the degree of linear dependence among two variables. If two variables ' $x$ ' and ' $y$ ' are so related, where ' $x$ ' is the conductivity of the lake and were ' $y$ ' is represented by either the phytoplankton or the lesser flamingos, the variables in the magnitude of one variable tend to be accompanied by variations in the magnitude of the other variable, they are said to be associated. Therefore, correlation as a statistical tool helps to ascertain whether or not two or more variables are associated and, if they are associated, the degree and direction of their correlation.

$$
r=\frac{n\left(\sum x y\right)-\left(\sum x\right)\left(\sum y\right)}{\sqrt{\left[n\left(\sum x^{2}\right)-\left(\sum x\right)^{2}\right]}\left[n\left(\sum y^{2}\right)-\left(\sum y\right)^{2}\right]}
$$

Where, $\mathrm{r}$ is the Pearson correlation coefficient, $\mathrm{N}$ is the sample size, $\sum x y$ is the sum of the products of paired scores, $\sum \mathrm{x}$ is the sum of $\mathrm{x}$ scores, $\sum \mathrm{y}$ is the sum of $\mathrm{y}$ scores, and $\sum \mathrm{x}^{2}$ is the sum of squared $\mathrm{x}$ scores.

The student $\mathrm{T}$-test was used to test for the significance of the correlation coefficient. The computed t-statistic derived from Equation (3) was compared with the tabulated t-value of the student t-distribution at the $n$ - 2 degrees of freedom and 5\% significance level.

$$
t_{n-2}=r \sqrt{\frac{(n-2)}{1-r^{2}}}
$$

Where, $\mathrm{n}$ represents the length of the data used, $n-2$ is the degree of freedom, $n-2$ is the computed t-statistic, and $r$ is the Pearson correlation coefficient.

The correlation coefficient was deemed to be notable if the computed value of $t$ was greater than the tabulated value at the 5\% significance level. This is usually conducted to ascertain whether the linear relationship in the sample data is strong enough to model the population's relationship.

\section{RESULTS AND DISCUSSION}

\section{Data quality control}

In this section, results of data quality control are propounded and their suitability for the study established. Specifically, this section propounds the results of the homogeneity test. Figures 2 and 3 show simple mass curves for rainfall and temperature, respectively. It can be noticed from Figures 2 and 3 that the rainfall and temperature data sets were homogeneous, owing to the resistant straight-line plots. It can be noted that generally, the rainfall has been gradually accruing, leading to an increment in the surface runoff, most of which subsequently ended up in the lake.

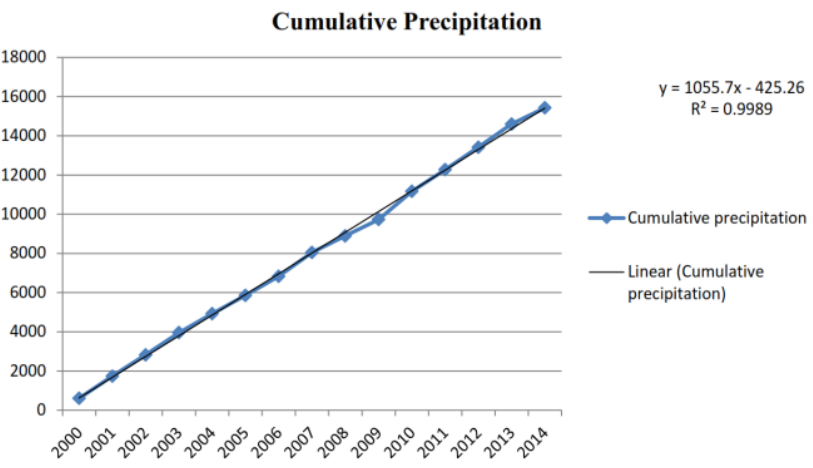

Figure 2. Single mass curve, cumulative annual rainfall

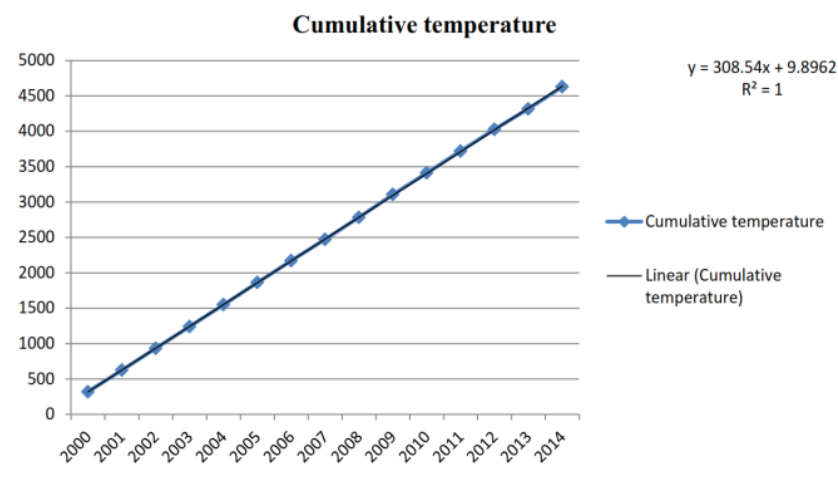

Figure 3. Single mass curve, cumulative annual temperature 
Past and present climatic record of Lake Nakuru from 2000 to 2014

Trend analysis of climatic data

Trends in rainfall patterns from 2000 to 2014. Lake Nakuru basin's mean annual rainfall patterns marked variability with major rainfall intensification in 2000 to 2001 and 2009 to 2010 , with the highest $(120 \mathrm{~mm})$ recorded in 2010 (Figure 4).

Trends in temperature patterns from 2000 to 2014. Mean annual temperatures have been on a lessening trend during the period 2000 to 2014 , with the highest temperatures being recorded in $2000\left(26.6^{\circ} \mathrm{C}\right)$ and $2009\left(27^{\circ} \mathrm{C}\right)$ (Figure 5). Evaporation in the Lake Nakuru basin shows a declining trend over the study period (Figure 6). However, the noticed decrement in evaporation from 2009 is consistent with the increment in rainfall noticed in Figure 4 and temperature decrement noticed in Figure 5.

Alterations in the lake levels (depth and surface area) 2009 to 2014. Time series of Lake Nakuru levels (depth). Lake Nakuru levels have risen from 2009 to 2014 (Figure 7). As seen in Figure 7, the mean depth of the lake rapidly increased during the study period (2009 to 2014). This could have been caused by increased rainfall during the study period, leading to increased surface runoff and direct rainfall into the lake. The increased water levels led to the flooding of the lake, which further lowered the conductivity of the lake as more freshwater was added to it.

\section{Alterations in the lake surface area}

Lake Nakuru's surface area increased from $31.8 \mathrm{~km}^{2}$ in January 2010 to a high of $54.7 \mathrm{~km}^{2}$ in Sept 2013 (Figure 8 and 9), an increment of $22.9 \mathrm{~km}^{2}(71.9 \%)$. This led to the submergence of $60 \%$ of the transport infrastructure in Lake Nakuru National Park and the park's main gate during this period, thereby displacing wildlife. At the highest level, the lake expanded and submerged areas that have never been recorded in the last 100 years (Figure 9). The extent of the flooded area and the impacts are illustrated in the image data and digitized maps shown in Figure 10.

\section{Conductivity, phytoplankton levels, and the lesser flamingos populations \\ Conductivity levels}

The mean conductivity of Lake Nakuru lessened from 2009 to 2014 (Figure 11).

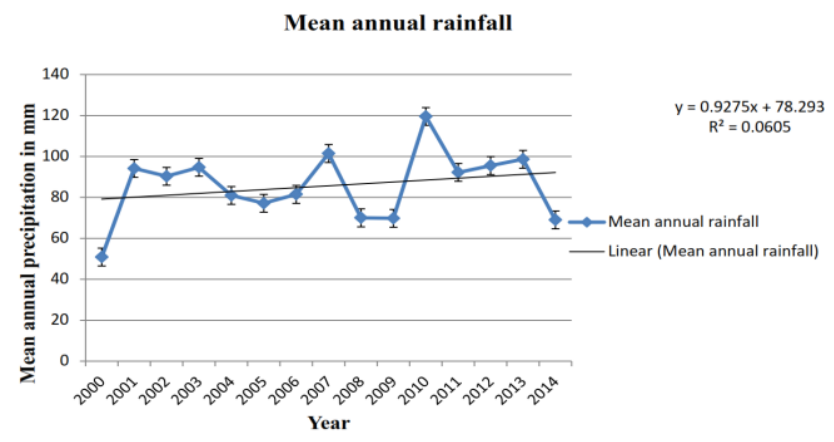

Figure 4. Mean annual rainfall patterns for the period 2000 to 2014

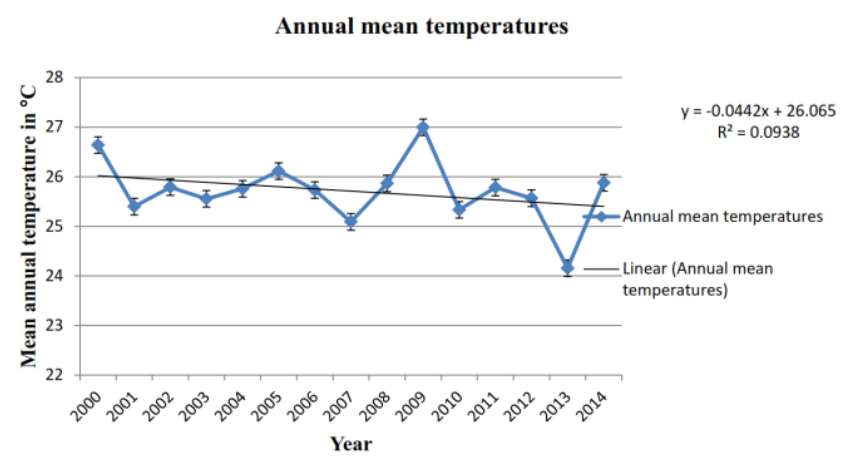

Figure 5. Mean annual temperatures from the year 2000 to 2014

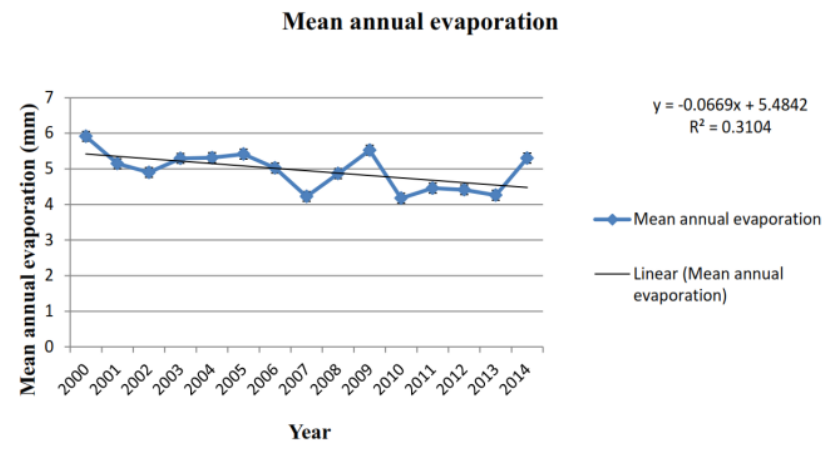

Figure 6. Mean annual evaporation patterns for the year 2000 to 2014

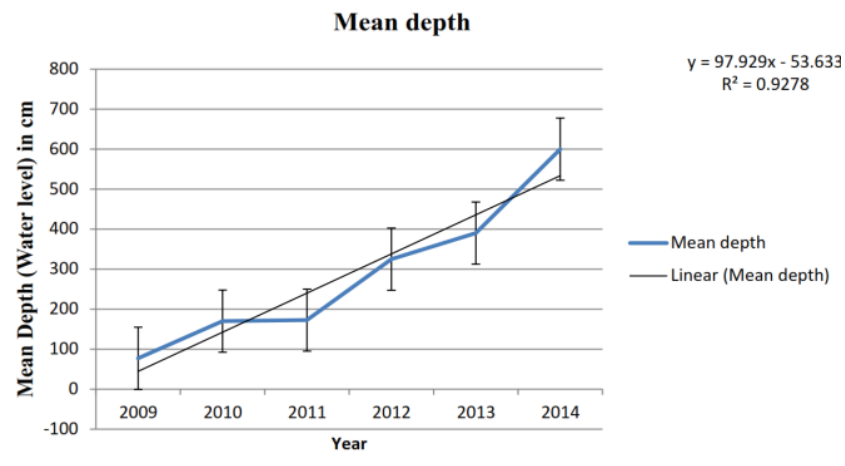

Figure 7. Alterations in the mean depth of Lake Nakuru from 2009 to 2014

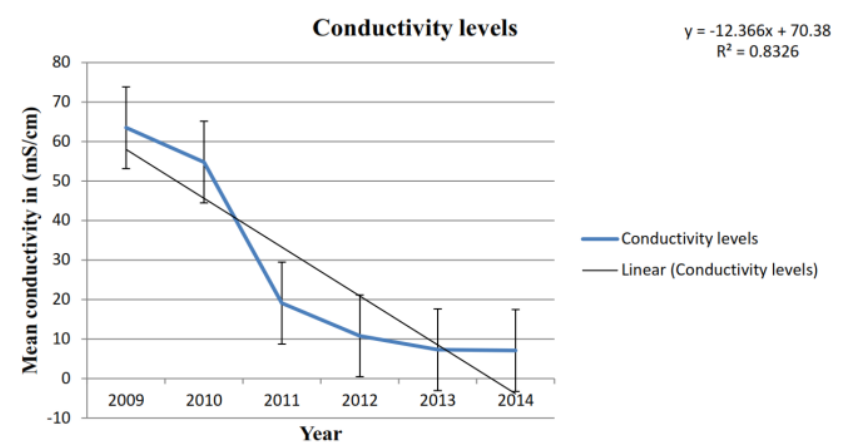

Figure 11. Trend in mean conductivity levels from 2009 to 2014 in Lake Nakuru 

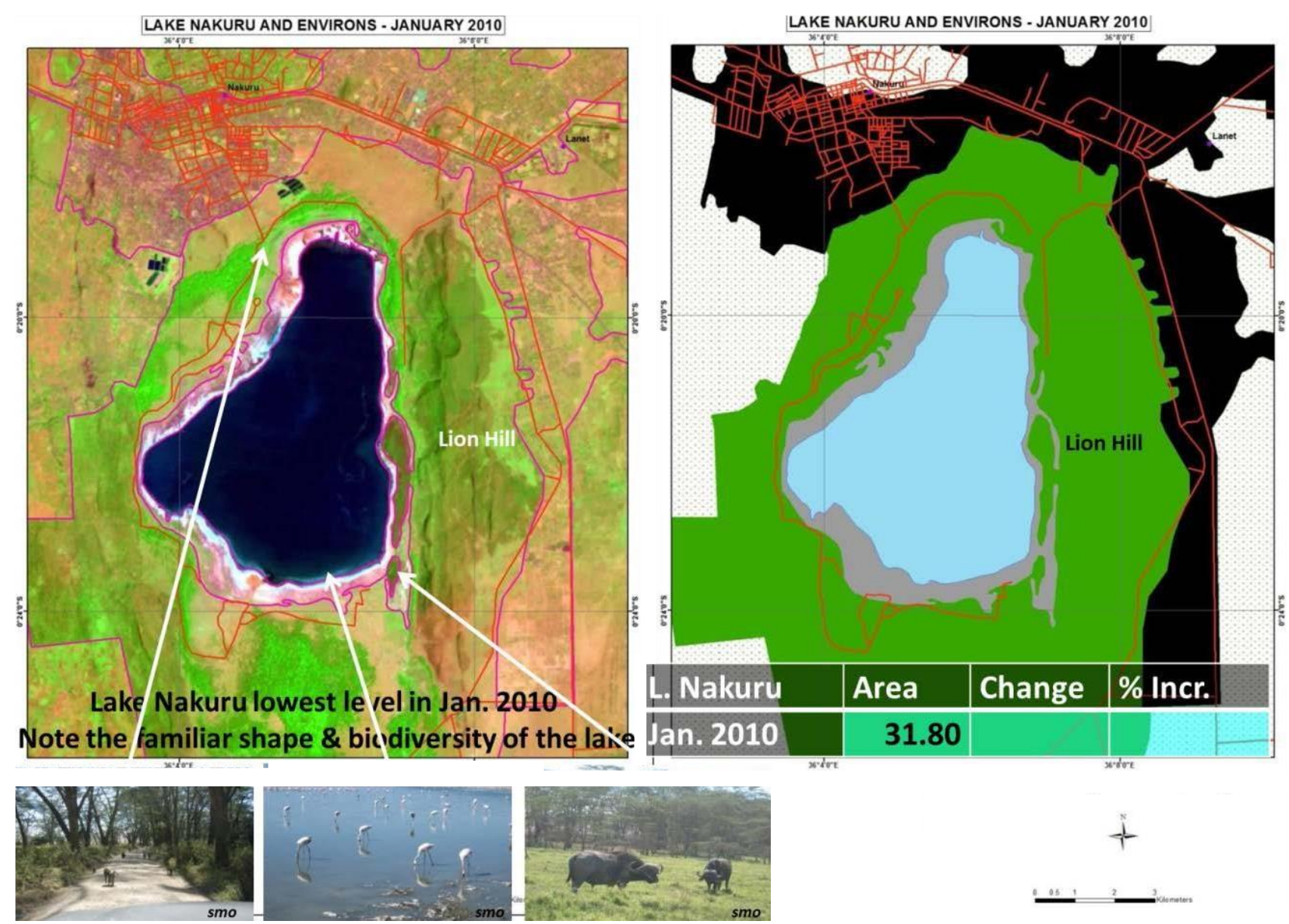

Figure 8. Alterations in the surface area of Lake Nakuru between January 2010 and 2013 (Source: Onywere et al. 2013)

This coincided with the beginning of the rains from 2010, as shown in Figure 4. The lake's declining conductivity could result in the loss of phytoplankton (reduction in food supply) upon which the lesser flamingos feed. This could eventually lead to the migration of the lesser flamingos from the lake. This is because as more freshwater was added to the lake, it lowered the conductivity of the lake. After all, freshwater has low conductivity, and the increment in water levels dilutes mineral concentrations.

\section{Phytoplankton levels}

The phytoplankton levels in Lake Nakuru were quite variable for 2009 to 2014, as shown by Figure 12 .

Notably, however, a general reduction in the phytoplankton levels, coinciding with the rains' onset from 2010, as shown in Figure 4. Phytoplankton levels lessened from 606 Units/mL in 2010 to 187 Units/mL in 2012. However, there was an increment in the phytoplankton levels to 321 Units/mL in 2013, which could have been caused by alterations in phytoplankton species composition and diversity that in turn affected their abundance due to alterations in the chemical and physical properties of the water (Kihwele et al. 2014).

\section{Lesser flamingo populations}

The number of lesser flamingos drastically lessened from the beginning of the rains in 2010 (Figure 13) from 41,592 in 2010 to 10,168 in 2011 and further reduced to 110 in 2012. This pattern follows that of lessening phytoplankton levels shown in Figure 12.

Phytoplankton levels

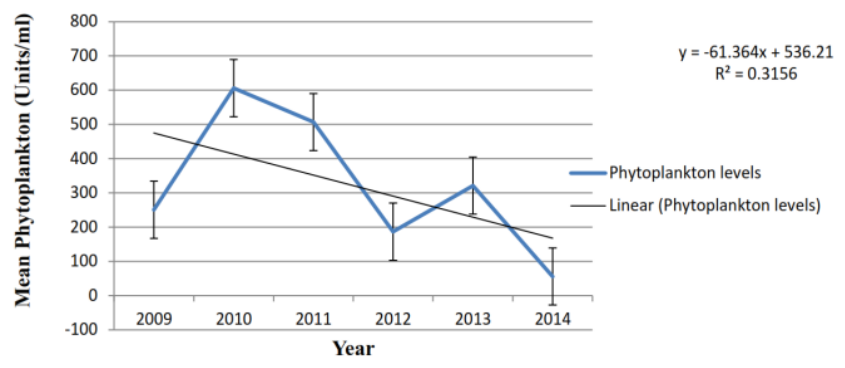

Figure 12. Trend in mean phytoplankton levels in Lake Nakuru from 2009 to 2014 

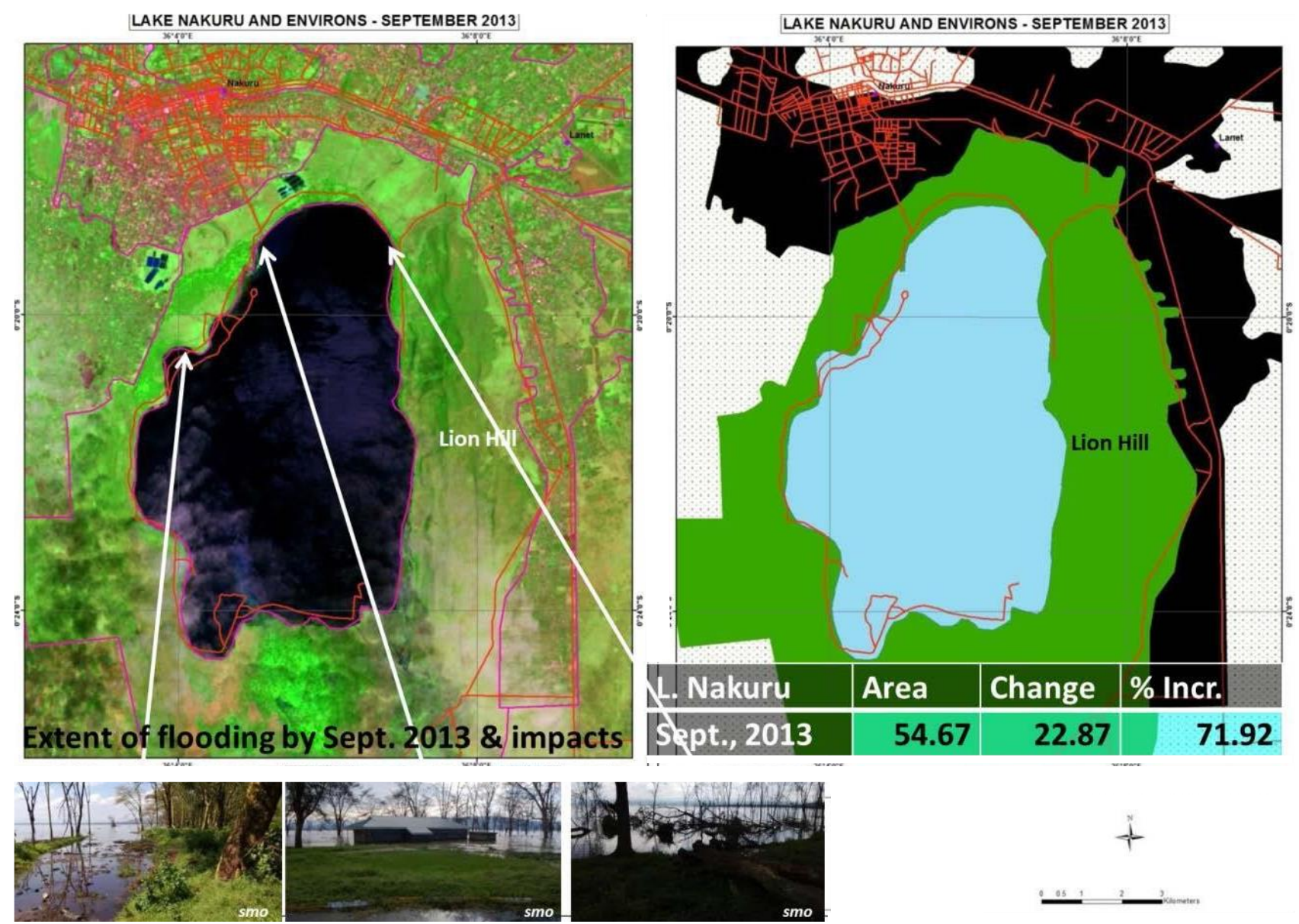

Figure 9. Lake Nakuru highest water level in September 2013 (Source: Onywere et al. 2013)

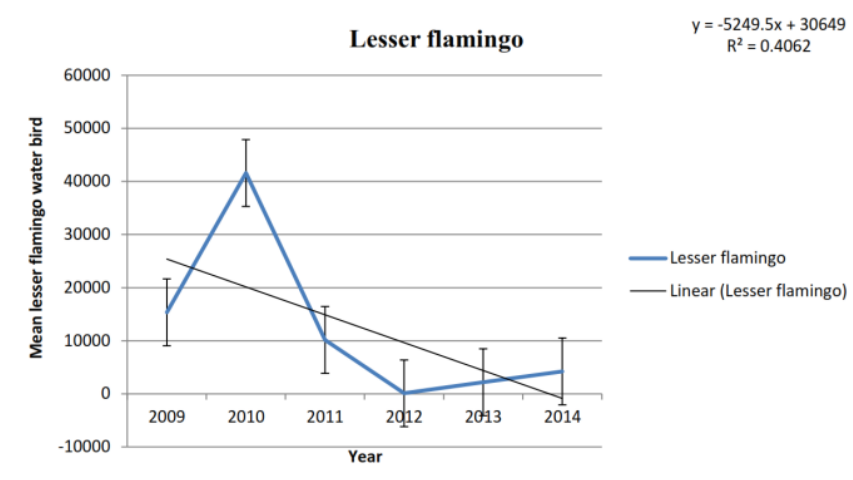

Figure 13. The trend in the number of lesser flamingos for the period 2009 to 2014

Correlation between alterations in lake conductivity and alterations in population estimates of the phytoplankton and the lesser flamingo

The findings in Table 1 showed a nonsignificant positive correlation between conductivity and phytoplankton $(\mathrm{r}=0.437, \mathrm{p}=0.386)$. The results in Table 2 showed a notable positive correlation between conductivity and the lesser flamingo $(\mathrm{r}=0.767, \mathrm{p}=0.075)$. The findings in
Table 3 also showed a positive correlation between phytoplankton and the lesser flamingo $(r=0.731, \mathrm{p}=0.099)$.

Table 1. Correlation of alterations in lake conductivity to alterations in population estimates of the phytoplankton in Lake Nakuru during the study period (2009 to 2014)

\begin{tabular}{|c|c|c|c|}
\hline & & $\begin{array}{c}\text { Conductivity } \\
\text { in }(\mathrm{mS} / \mathrm{cm})\end{array}$ & $\begin{array}{c}\text { hytoplankton } \\
\text { (Units/mL) }\end{array}$ \\
\hline \multirow[t]{3}{*}{$\begin{array}{l}\text { Conductivity in } \\
(\mathrm{mS} / \mathrm{cm})\end{array}$} & $\begin{array}{l}\text { Pearson } \\
\text { correlation }\end{array}$ & 1 & .437 \\
\hline & Sig. (2-tailed) & & .386 \\
\hline & $\mathrm{N}$ & 6 & 6 \\
\hline
\end{tabular}

Table 2. Correlation of the alterations in electrical conductivity to alterations in population estimates of the lesser flamingo in Lake Nakuru from 2009 to 2014

\begin{tabular}{llcc}
\hline & & $\begin{array}{c}\text { Conductivity } \\
\text { in }(\mathbf{m S} / \mathbf{c m})\end{array}$ & $\begin{array}{c}\text { Lesser } \\
\text { flamingo } \\
\text { water bird }\end{array}$ \\
\hline $\begin{array}{l}\text { Conductivity in } \\
(\mathrm{mS} / \mathrm{cm})\end{array}$ & $\begin{array}{l}\text { Pearson } \\
\text { correlation }\end{array}$ & 1 & .767 \\
& Sig. (2-tailed) & & \\
& $\mathrm{N}$ & 6 & .075 \\
& & 6 \\
\hline
\end{tabular}



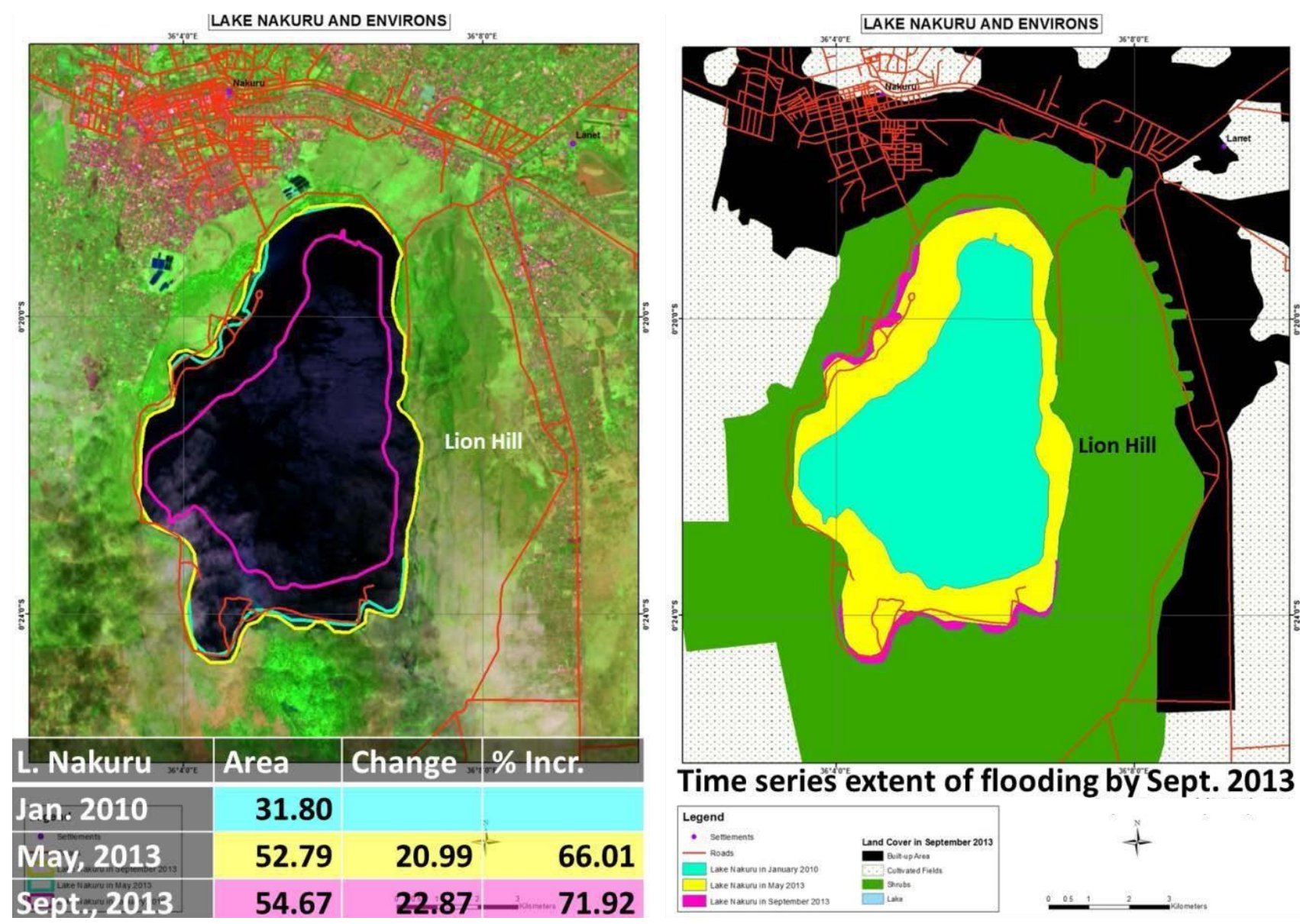

Figure 10. Time series extent of flooding in Lake Nakuru from a low area of $31.8 \mathrm{~km}^{2}$ in January 2010 to a high of $54.7 \mathrm{~km}^{2}$ in Sept 2013, a total increment of $22.9 \mathrm{~km}^{2}$ (71.9\%) (Onywere et al. 2013)

Table 3. Correlation of the alterations in the population estimates of the lesser flamingo in Lake Nakuru to alterations in the population estimates of the phytoplankton from 2009 to 2014

\begin{tabular}{|c|c|c|c|}
\hline & & $\begin{array}{c}\text { Lesser flaming } \\
\text { water bird }\end{array}$ & $\begin{array}{c}\text { Phytoplankton } \\
\text { (units/mL) }\end{array}$ \\
\hline \multirow[t]{3}{*}{$\begin{array}{l}\text { Lesser flamingo } \\
\text { water bird }\end{array}$} & $\begin{array}{l}\text { Pearson } \\
\text { correlation }\end{array}$ & 1 & .731 \\
\hline & $\begin{array}{l}\text { Sig. }(2- \\
\text { tailed })\end{array}$ & & .099 \\
\hline & $\mathrm{N}$ & 6 & 6 \\
\hline
\end{tabular}

Projections of the climatic data (temperatures, evaporation, and rainfall) for the period 2017-2100

Lake Nakuru's future climate scenarios comprising near-surface temperature, rainfall, and evaporation were plotted for 2017 to 2100 (projection) for RCP2.6 and RCP8.5 relative to the baseline period 1971 to 2000 . The results obtained are sequentially propounded in the subsections that follow.

\section{Near-surface temperature projections}

Future alterations in annual temperature for Lake Nakuru under RCP2.6 and RCP8.5 for the period 2017 to
2100 relative to the baseline period 1971 to 2000 are propounded in Figures 14 and 15, respectively.

Temperature projections indicate an accruing trend with a $1.2^{\circ} \mathrm{C}$ increment for 2071 to 2100 mean alterations for RCP2.6 (Figure 14), whereas there is a $4.8^{\circ} \mathrm{C}$ increment for 2071 to 2100 mean alterations for RCP8.5 (Figure 15). The likely causes of the accruing trend of temperature under both RCP2.6 and RCP8.5 could be accruing levels of greenhouse gas concentrations in the atmosphere during the projected period. Notably, however, the rate of temperature increment in RCP2.6 is lower than that of RCP8.5.

\section{Rainfall projections}

Future alterations in rainfall for Lake Nakuru under RCP2.6 and RCP8.5 were plotted for 2017 to 2100 relative to the baseline period 1971 to 2000 are shown in Figures 16 and 17 , respectively.

The rainfall projection from RCP2.6 and RCP 8.5 shows a $10 \%$ and $20 \%$ increment in rainfall for 2071 to 2100 .

\section{Evaporation projections}

Future alterations in evaporation for Lake Nakuru under RCP2.6 and RCP8.5 for the period 2017 to 2100 relative to 
the baseline period 1971 to 2000 are shown in Figures 18 and 19.

Relative evaporation is projected to raise by $10 \%$ and $20 \%$ for 2071 to 2100 mean changes for RCP2.6 and RCP8.5, respectively.

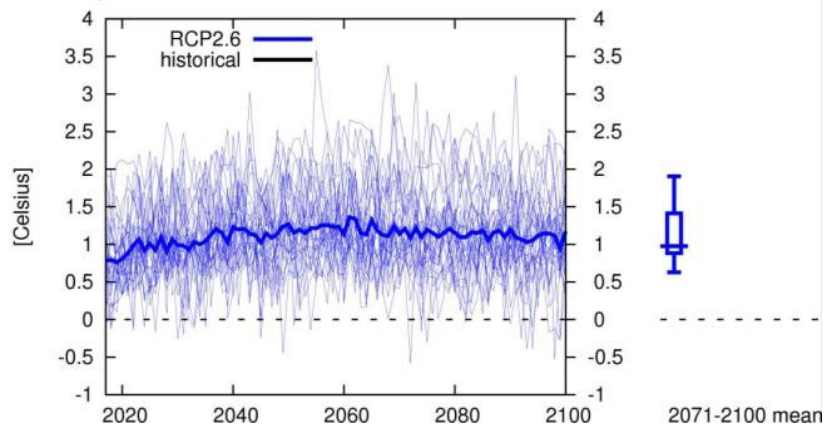

Figure 14. Near-surface temperature projection for RCP 2.6 for the Lake Nakuru area from 2017 to 2100 shows a $1.2^{\circ} \mathrm{C}$ increment for 2071 to 2100 mean alterations

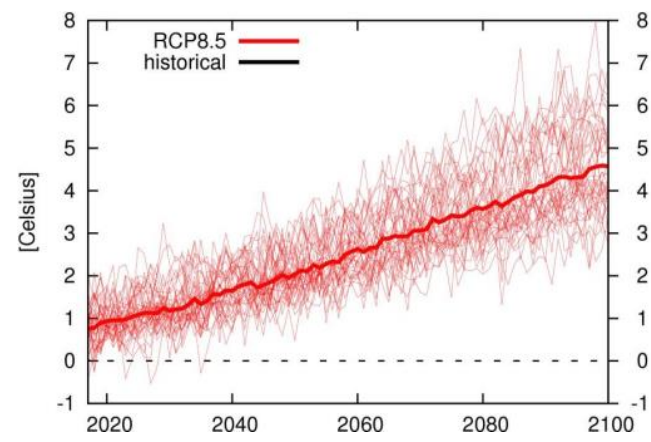

2071-2100 mean

Figure 15. Near-surface temperature projection for RCP8.5 for the Lake Nakuru area from 2017 to 2100 shows a $4.8^{\circ} \mathrm{C}$ increment for 2071 to 2100 mean alterations

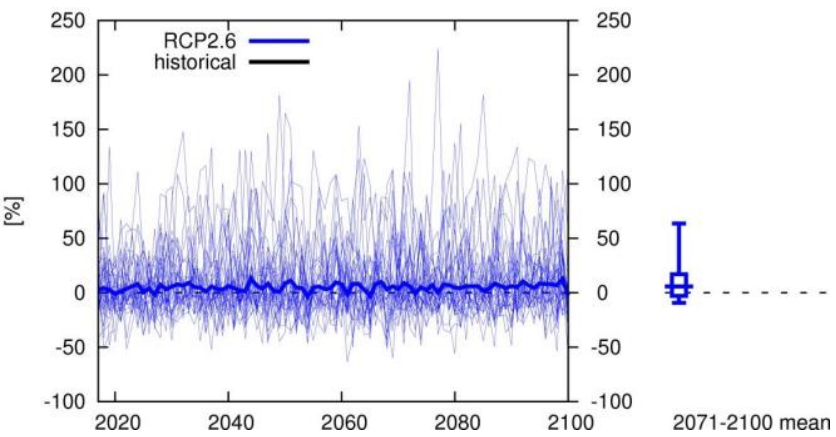

Figure 16. Rainfall projections for RCP2.6 for Lake Nakuru

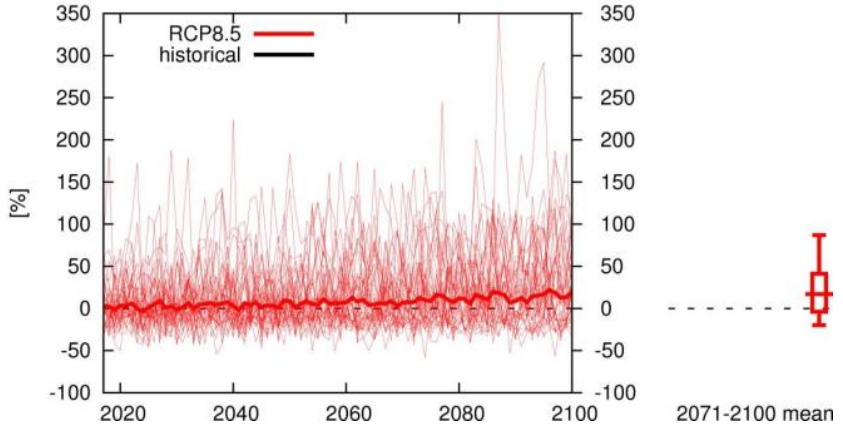

Figure 17. Rainfall projections for RCP8.5 show a $20 \%$ increment in rainfall in the Lake Nakuru area for 2071 to 2100 mean alterations

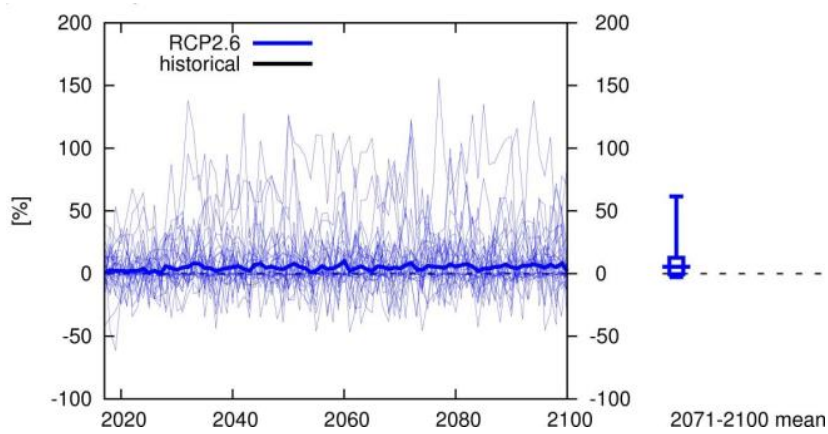

Figure 18. Relative evaporation alteration for RCP2.6 for the Lake Nakuru for 2071 to 2100

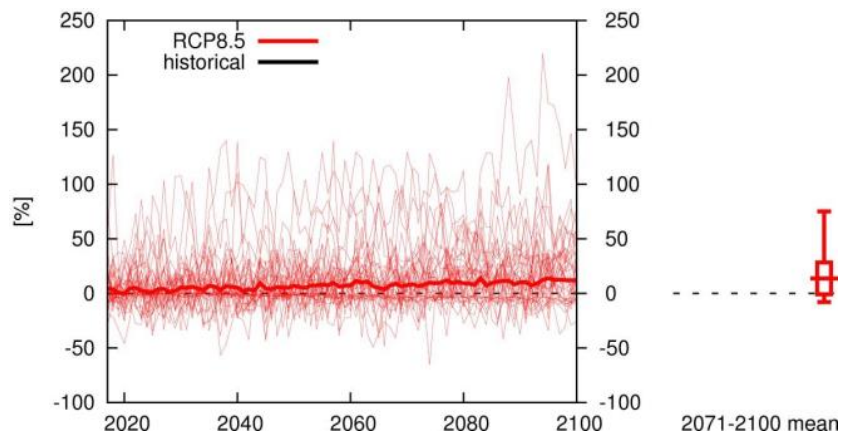

Figure 19. Relative evaporation alteration for RCP8.5 for Lake Nakuru

\section{Discussions}

As drawn in Figure 4, it can be concluded that rainfall has increased since 2010, and this may have significantly affected the accruing water levels in lakes, as shown by the images obtained from (Onywere et al. 2013). Figure 7 also depicts that the lake's depth has gradually increased since the beginning of the rain in 2010. This can be strongly associated with increased surface runoff and lake catchment improvements from Njoro, Makalia, Larmudiac, and Enderit Rivers and direct rainfall to lakes. 
Figures 5 and 6 depict that temperature and evaporation have been rising from 2007 to 2009, the same period when there was little/no rain, and drastically lessened from 2009 to 2010 , the beginning of the rainy season. According to Trenberth (2011), an increment in temperature usually leads to an increment in evaporation and, therefore, drought. Heating about $7 \%$ per $1{ }^{\circ} \mathrm{C}$ raises the water holding capacity of the atmosphere. This is noticed in studies with temperatures and evaporation rising from 2007 to 2009 , which increased the ability to water retaining of the atmosphere, thus the beginning of rain in 2009.

According to the IPCC (2007), climate change is clearly more and easily accessed by temperature. However, atmospheric moisture changes, atmospheric circulation, and rainfall are also ascertained because the overall climate system is generally influenced. The capacity to withstand atmospheric moisture increment as the temperature becomes higher at a rate of about $7 \%$ per ${ }^{\circ} \mathrm{C}$ (Trenberth et al., 2003). Collectively, changes in the hydrological cycle are influenced, particularly the characteristics of rainfall (type, intensity, amount, duration, frequency) and extremes (Trenberth et al., 2003). The increased water vapor convergence guides to heavier rainfall but a reduction in time and/or frequency in the weather system, given that the total amount changed a little. Therefore, it can be concluded that a slight increment in temperature induces a tighter hydrological cycle because the evaporation rate is also increased, which has a direct impact on cloud formation since intense rainfall is affected as atmospheric water containment capacity increases, as noticed in 2010.

Seasonal hydrological budget changes significantly affect endorheic lakes that may be extreme, resulting in severe algal biomass accidents and significant changes in community composition, as has been noticed in Lake Nakuru.

As more water is added to the lake, it liquidizes the mineral concentration, thereby lessening the lake's electrical conductivity. Freshwater has low conductivity. According to the study in Figure 11, the conductivity level began to decline in 2010, after the rain. The relationship between lake water conductivity and lake depth examined in this study reflects the cycle of concentration and dilution of the lake due to evaporation during the dry season followed by replenishment from river in-flow and water run-off during the wet season. These hydrological cycles profoundly affect aquatic biota in the lake (Githaiga, 1997).

The correlation coefficient in Table 1 showed changes in lake conductivity and corresponding changes in phytoplankton population estimates. The undistinguished coefficient between conductivity and phytoplankton $(\mathrm{r}=$ $0.437, p=0.386$ ) reflects the cycle of lake dilution due to replenishment from the river in-flow and water run-off during the rainy season. Some aquatic species adjusted to life in highly alkaline water at Lake Nakuru and achieved a very high biomass level that serves as food for the main feeder. The blue-green algal species, Arthrospira fusiformis, is one such species, and it is the leading food of the lesser flamingos. Thus, when the level of conductivity of the lake lessened, the rate of phytoplankton in the lake also reduced because the conditions were not conducive for them to bloom.

Table 2 shows that the conductivity had a strong positive correlation, with a lesser flamingo $(r=0.767, \mathrm{p}=$ 0.075). This entails that low conductivity impacts the growth of phytoplankton by making an undesirable environment for raising phytoplankton. Because the lesser flamingo relies on phytoplankton for their feed, it suggests that phytoplankton's denseness can be a notable predictor of the lesser flamingo occurrence in Lake Nakuru. The noticed correlation, which is high and strong $(\mathrm{r}=0.731, \mathrm{p}=$ 0.099 ) between phytoplankton and lesser flamingo shown in Table 3, confirms that in saline lakes, the distribution of lesser flamingo is affected by the availability of feed.

Figures 14 to 19 show an increment in temperature, rainfall, and evaporation for 2017 to 2100 under RCP2.6 and RCP8.5 relative to the baseline period 1971 to 2000 acquired from the Model Combined Model Intercomparison Phase 5 (CMIP5) multi-model ensemble.

As you will notice, the rising rate in temperature, rainfall, and relative evaporation in RCP8.5 are looked to be higher than in RCP2.6. This is assigned to the fact that RCP8.5 is qualified by a business-as-usual scenario with rising greenhouse gas emissions over time, conducing to high levels of greenhouse gas concentrations equated to RCP2.6, which exemplifies an all-out attempt to restrict warming global to below $2^{\circ} \mathrm{C}$ with emissions declining sharply after 2020 and zero from 2080 onwards.

Based on the rainfall projection (Figures 16 and 17), it is estimated that the lake's average depth will raise over time because the replenishment is strongly affected by rainfall, which is also positively associated with the temperature. Therefore, an increment in rainfall will result in an increment in discharge during the projection period. As explained before, a slight increment in temperature induces a stronger hydrological cycle. Therefore, because the projection indicates an increment in temperature level, it is estimated that the hydrological cycle will be very strong during the projection period, which assumes that ultimately, the hydrological cycle will be altered, resulting in more intense rain, characterized by thunderstorms (Trenberth 2011).

The raising replenishment during the projection period will lessen the level of conductivity in the lake, indicating the lake's increased concentration and dilution cycle due to evaporation during the dry season followed by replenishment by the river in-flow and water run-off during each wet season. The decrement in conductivity levels will consequently alter the condition of the lake, making an unfavorable environment for phytoplankton thrives, thereby cutting down the handiness of feed for lesser flamingos and finally, cutting down the amount of lesser flamingos in lakes due to their migration to other lakes which harbor the food supply of their choice and with the appropriate living conditions.

Because the lake area has a negative rainfall/evaporation deficit, the rising temperature will induce a higher evaporation rate and, therefore, higher conductivity due to evaporative concentration during the projected period. 


\section{Conclusions}

The study discovered that climate change and climate variability could cause substantial effects on saltwater lakes by making modifications in their physicochemical traits. This has been proved by the variations in rainfall and temperature, which affect the phytoplankton availability, ascertained by the chemical and physical traits of the lake. There were fluctuations in the lesser flamingos' population due to climate variability. These were because of the alterations in rainfall that influenced the physicochemical composition, lake depth, and the surface location of the lake, which ultimate effect is discovered in the abundance of the phytoplankton (foods for the lesser flamingos). This study indicates that the shift and succession in phytoplankton species relate to the variations in the physicochemical elements of the lake, especially the conductivity, which are greatly affected by the variability of climate. The study also proposes that the population dynamics of the lesser flamingos may be affected by using the availability of their essential meals, Arthrospira fusiformis, which is in turn influenced by physicochemical properties of water and also by weather variability. Based on future projections, it is hoped that the lake will maintain growing in surface area and depth by the year 2100 because of increased thereby influencing the populations of the lesser flamingos and phytoplankton, as the physicochemical elements of the lake will also change in the course of the projected period.

\section{REFERENCES}

CBD. Convention on Biological Diversity. Convention on Biological Diversity, United Nation 1992. http://www.cbd.int/doc/legal/cbden.pdf. DOI: 10.4324/9781315071770.

Climate Action Network. 2009. Kenya: A country of Growing Despair: Frontline View. Voices from communities in developing countries most affected by escalating climate change impacts. climatenetwork.org/eco/barcelona-2009-ecos/Voice2.pdf

Githaiga JM. 1997. Utilization patterns and inter-lake movements of the Lesser Flamingo and their conservation in Saline Lakes of Kenya. In Howard G (ed) Conservation of 166 the Lesser Flamingo in Eastern Africa and beyond. IUCN, Nairobi, Kenya.

IGAD. 2007. IGAD Environment Outlook. Intergovernmental Authority on Development (IGAD). Djibouti.

IPCC. 2007. Climate Change 2007: Synthesis Report. Contribution of Working Groups I, II, and III to the Fourth Assessment Report of the
Intergovernmental Panel on Climate Change. Intergovernmental Panel on Climate Change, Geneva, Switzerland.

IPCC 2012. Managing the Risks of Extreme Events and Disasters to Advance Climate Change Adaptation. A Special Report of Working Groups I and II of the Intergovernmental Panel on Climate Change. Cambridge University Press, Cambridge, UK.

IPCC. 2014. Climate Change 2014: Synthesis Report. Contribution of Working Groups I, II, and III to the Fifth Assessment Report of the Intergovernmental Panel on Climate Change. Intergovernmental Panel on Climate Change, Geneva, Switzerland.

Kihwele ES, Lugomela C, Howell KM. 2014. Temporal changes in the Lesser Flamingos population (Phoenicopterus minor) in relation to phytoplankton abundance in Lake Manyara, Tanzania. Open J Ecol 4: 145-161. DOI: 10.4236/oje.2014.43016.

Kimberly MJ. 1999. Microcystins in components of twelve New Hampshire lakes of varied trophic status. UNH Centre for Freshw Biol Res 1 (4): 45-56.

KNMI. 2015. KNMI Climate Change Atlas. 2015. https://climexp.knmi.nl/plot_atlas_form.py

KWS. 2009; 2010; 2011; 2012; 2013; 2014. KWS Bi-annual Waterfowl Count Report-Kenya Rift Valley Lakes

Moss RH, Edmonds JA, Hibbard KA, Manning MR, Rose SK, Van Vuuren DP, Wilbanks TJ. 2010. The next generation of scenarios for climate change research and assessment. Nature 463 (7282): 747-756. DOI: $10.1038 /$ nature08823.

Mutai CC, Ochola S, Mukiira H, Gachimbi LN, Otiono M, King'uyu SM, Marigi SN. 2010. Climate Change and Variability. State of the Environment in Kenya Report. Ministry of Environment and Natural Resources, Nairobi, Kenya.

NEMA. 2009. The 4th National Report to the Conference of Parties of the Convention on Biological Diversity. Nairobi, Kenya.

NEMA. 2011. Kenya State of the Environment and Outlook 2010. National Environment Management Agency, Government of Kenya.

Odada EO, Raini J, Ndetei R. 2006. Lake Nakuru: Experience and Lessons Learned Brief. Lake Basin Management Initiative: Main Report, 299-321

Pomeroy DE, Dranzoa C. 1997. Methods of studying distribution, diversity, and abundance of birds in East Africa - some quantitative approaches. Afr J Ecol 35 (2): 110-123. DOI: 10.1111/j.13652028.1997.077-89077.x.

Stockholm Environment Institute. 2009. The Economics of Climate Change in Kenya, SEI, Oxford.

Taylor KE, Stouffer RJ, Meehl GA. 2012. An overview of CMIP5 and the experiment design. Bull Amer Meteorol Soc 93 (4): 485-498. DOI: 10.1175/BAMS-D-11-00094.1.

Trenberth K. 2011. Changes in precipitation with climate change. Clim Res 47 (1-2): 123-138. DOI: 10.3354/cr00953.

Trenberth KE, Dai A, Rasmussen RM, Parsons DB. 2003. The changing character of precipitation. Bull Am Meteorol Soc 84 (9): 1205-1217. DOI: 10.1175/BAMS-84-9-1205.

Van Vuuren DP, Riahi K, Moss R, Edmonds J, Thomas A, Hibbard K, Hurtt GC, Kram T, Krey V, Lamarque JF, Masui T. 2011. The representative concentration pathways: an overview. Clim Change 109 (1): 5-31. DOI: 10.1007/s10584-011-0148-z. 